\title{
Orthodontic President Summit Meeting
}

\author{
Hossain MZ BDS, PhD
}

22nd TAO (Taiwan Association of Orthodontics) National Annual Meeting and 2nd WIOC (World Implant Orthodontic Conference) Meeting was held at Taipei International Convention centre. Between 10-12 December, 2010.

The main theme of the conference was" World Trends of Anchorage development-TADs" . Dedicated team of organizing comittee of the 2nd WIOC in conjunction of with the 22nd Annual meeting of the TAO has worked hard to line up the best speakers in the world of orthodontics for a stimulating and outstanding progrm .

In addition to academic and clinical knowledge TAO was also dynamic to organize and sponsor the President Summit Meeting of International Orthodontic Organization. It was a great pleasure and honor in my part to attend that summit meeting to represent Bangladesh Orthodontic Society and and place our problem based agendas in the summit meeting. I was also honored as a chairperson in the Scientific Session . (Ban J Orthod \& Dentofac Orthop, April 2011; Vol1, No. 2, 38-42)

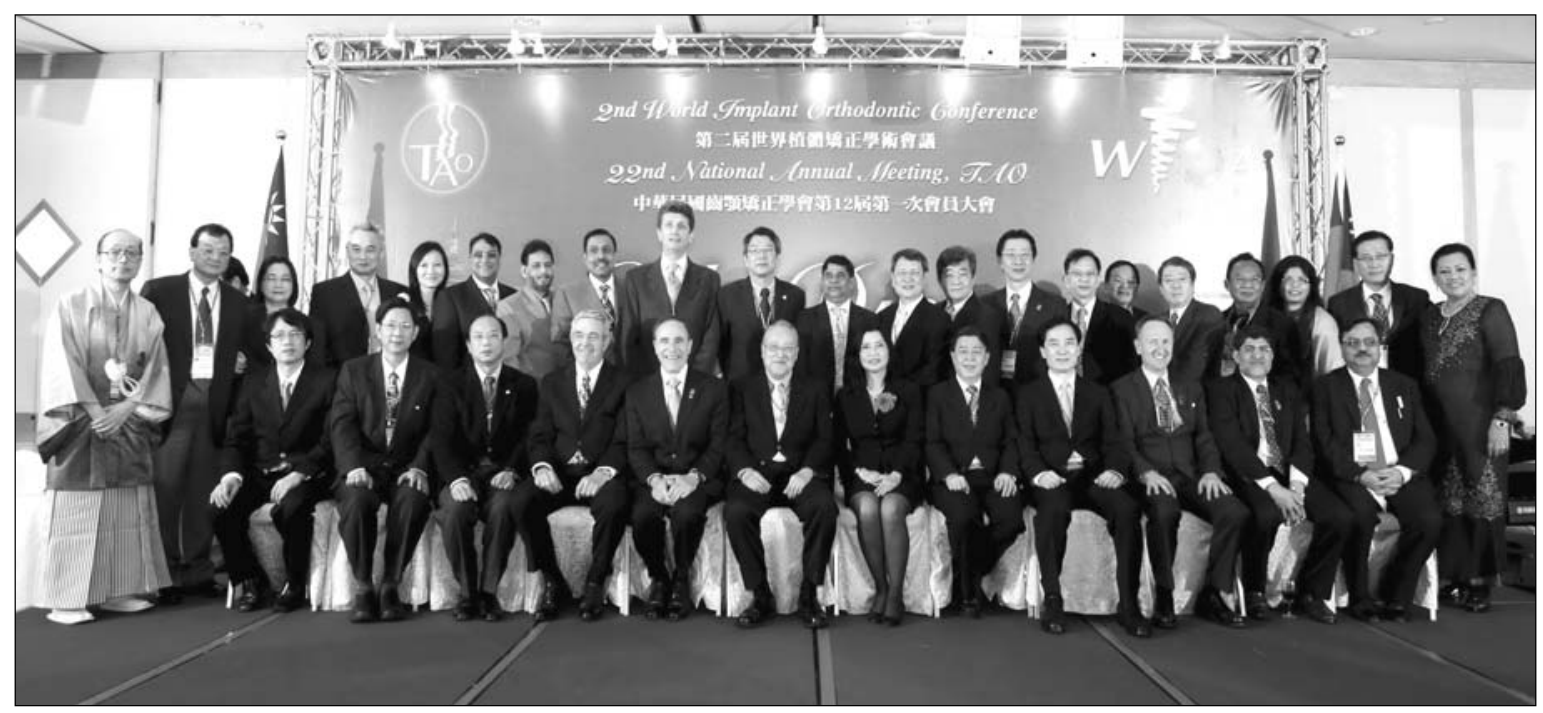

Delegates of the Summit Meeting

All the participants had open discussion. Frankly speaking, TAO was successful by arranging such Summit Meeting, as each member organization of WFO could share their present status of practing orthodontics (legal and logistic), research and orthodontic education. The results of this meeting proves that this policy is perfectly right and should be continued in the future too. Let me furnish the details of the summit meeting and some photographs of the conference which may update overall situation of world orthodontics:

\section{Time \& Venue}

December 11, 2010

11:30 AM - 13:30PM

Ambassador III

Taipei World Trade Center

Taipei, Taiwan, R.O.C.

\subsection{Call to Order \& Welcome Address}

TAO President Dr. Ching-huei, Horng call the meeting to order at exactly 11:30 AM and welcome and thank all in attendance. He express his sincere appreciation for the great supports from all the friends from the APOS and WFO affiliated organizations to share the scientific knowledge, technology, clinical skills and friendship with each other.

1.1 WFO Secretary General Dr. William H. DeKock address

1.2 AAO President Dr. Lee Graber address

1.3 Self Introduction of all the attendees

2.0 Roll Call \& Determination of Quorum

\section{Substitute Presidents}

Japanese Orthodontic Society (JOS):

Professor Dr. Keiji Moriyama represent the President Professor Dr. Shigemi Goto. 
Bangladesh Orthodontic Society (BOS):

Dr. Md. Zakir Hossain represent the President Professor

Dr. Mohammad Emadul Haq

Japanese Association of Adult Orthodontics (JAAO):

Dr. Takehiko Daisaku represent the President

Dr. Motohiko Sato

\section{Absent}

Australian Society of Orthodontists (ASO):

President Dr. Mike Razza

Orthodontic \& Dentofacial Orthopedic Association of Nepal, President Dr. Praveen Mishra

Present

Forty Orthodontic Presidents, President-elect, Vice Presidents, WFO ECs and APOS ECMs and distinguished guests. They are:-

World Federation of Orthodontists, Secretary Genera

Dr. William H. DeKock

American Association of Orthodontists, President

Dr. Lee Graber

Asia Pacific Orthodontic Society, President

Dr. Kai-Who Loh

Asia Pacific Orthodontic Society, Vice President

Dr. Kazuo Tanne

APOS Secretary General, (ThaAO)

Dr. Jaruprakorn Tanan

WFO E.C. Asia \& Thai Associatioin of Orthodontists, President Dr. Somchai Satravaha

WFO, E.C. Asia \& Japanese Orthodontic Society, Director Dr. Keiji Moriyama

WFO E.C. Ocenia, Indonesian Association of Orthodontists Dr. Halim Himawan

Association of Orthodontists Singapore (AOS), President Dr. Vicpearly Wong

Association of Philippine Orthodontists (APO), President Dr. Jose Manuel R. Rivera

Association of Philippine Orthodontists (APO), President-elect Dr. Roberto B. Tan

Bangladesh Orthodontic Society (BOS), Secretary General Dr. Md. Zakir Hossain

Indian Orthodontic Society (IOS), President

Dr. Girish Karandikar

Indian Orthodontic Society, Immediate Past President

Dr. Om P. Kharbanda

Indonesian Association of Orthodontists (IAO), President.

Dr. Eky S. Soeria Soemantri

Korean Association of Orthodontists(KAO), President

Dr. Young-Guk Park

Korean Association of Orthodontists, Immediate Past President Dr. Kim Sang-Cheol

Malaysian Association of Orthodontists(MAO), President

Dr. Shalene Kereshanan

Malaysian Association of Orthodontists, Chairman, 2014 APOC

Dr. Noraini Binti Hj. Alwi
New Zealand Association of Orthodontists(NZAO), President Dr. Peter Fowler

Pakistan Association of Orthodontists(PAO), President Dr. Sheraz Burki

Pakistan Association of Orthodontists, Immediate Past President Dr. Amjad Mahmood

Pakistan Association of Orthodontists, APOS ECM, Dr. Mubassar Fida

Saudi Arabia Orthodontic Society(SAOS)

Dr. Mohammed T. Bukhary

Taiwan Association of Orthodontists(TAO), President Dr. Ching-Huei, Horng

Taiwan Associatioin of Orthodontists, Vice President Dr. Hsu Wei-Yung

Taiwan Associatioin of Orthodontists, Vice President Dr. Johnny J-L Liaw

World Implant Orthodontic Association(WIOA), President Dr. Y.C. Park

Japanese Association of Orthodontists(JAO), President

Dr. Tateshi Hiraki

Thai Associatioin of Orthodontists, President-elect

Dr. Chairat Charoemratrote

Association of Orthodontists Singapore, Treasure

Dr.

Japanese Association of Adult Orthodontics

Dr. Takehiko Daisaku

TAO Charter President

Dr. Hsiao-Dsung Fay

TAO International Development Committee Chairman, (TAO)

Dr. Yeong-charng Yen

TAO Advisor \& Immediate Past President

Dr. Ming-jeaun Su

TAO Advisor \& Past President

Dr. Chih-Peng Su

TAO Advisor \& Past President

Dr. Chia-tze Kao

TAO Scientific Committee Chairman

Dr. Eric Liou

TAO Members Benefits Committee Chairman

Dr. John Kuan-Fa Chang

TAO Deputy Secretary General

Dr. Mark Hen-ming Chang

TAO Secretariat

Ms. Wei-jun Chen

\subsection{Agenda}

3.1 Proposal from Bangladesh Orthodontic Society (BOS)

1. Orthodontics in Bangladesh is very developing stage; we are under tremendous pressure to produce qualified Orthodontists to meet the demand of densely populated country. We are lacking adequate number of teaching expertise. Fellow member organization may come forward to deliver lectures or conducting Hands on technique in contemporary Orthodontic techniques (eg;Use of Implant in Orthodontics) in Bangladesh. 
2. Complimentary Journals /periodicals may be exchanged among the member countries.

\section{Proposer}

Dr. Md. Zakir Hossain, BDS,PhD

Professor \& Head,

Dept. of Orthodontics \& Dentofacial Orthopedics

Dhaka Dental College \& Hospital, Bangladesh

Secretary General,

Bangladesh Orthodontic Society (BOS)

EC Member APOS

\subsection{Proposal from Asian Pacific Orthodontic Society (APOS)}

1. "a development of academic association for orthodontic professionals in the Asian Pacific regions completely independent on governmental control or politics".

2. we may have to discuss about the global standards for orthodontic education to generate the well-trained and qualified specialists, which may have already been defined by WFO.

Proposer

Professor Dr. Tanne, Kazuo D.D.S., Ph.D.

Vice President,

Asian Pacific Orthodontic Society

Executive Committee Member,

Asian Pacific Orthodontic Society

\subsection{Proposal from the Japanese Orthodontic Society (JOS)}

All the presidents briefly report the current news of the own society by turns to promote mutual understanding and friendship.

Proposer

Dr. Keiji Moriyama, D.D.S., Ph.D.

Professor and Chairman

Department of Maxillofacial Orthognathics

Tokyo Medical and Dental University Graduate School

Director,

International Committee, Japanese Orthodontic Society

Director,

Executive Committee, World Federation of Orthodontists

3.4 Proposal from Taiwan Association of Orthodontists (TAO)

1. The continuing of the International Orthodontic President Summit Meeting. We Orthodontic World have so many new challenges, need cooperation between different Associations/Societies. We also have so many opportunities to share our resources together. However, all of these need good management system. The Internatonal Orthodontic Presidents Summit Meeting offer the excellent platform and opportunities to let the Orthodontic Elites to cooperate together to develop the future Orthodontic Direction. We TAO sincerely wish this kind of meeting could be maintained for once every two years, We wish it could be under WFO structure and right now it is started with the combination of Central, East Asia and Ocenia.
2. The two Associations united together to invite the International renowned speakers to host the continuing education. The expenses for the continuing education for international renowned speakers increased a lot recently. It is more and more difficult for Orthodontic Association to sponser it alone. The travel distances and time between Asia cities are relatively less compared to intercontinental traveling. For example: the travel between Tokyo and Taipei, Manila to Taipei are both very short. We can ask the International renowned speakers to visit two countries to lessen the budget for the continuing education.

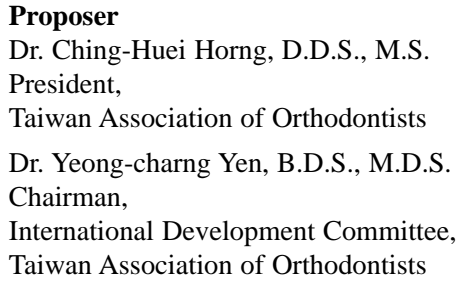

\subsection{Proposal from Malaysian Association of Orthodontists (MAO)}

The organisation of orthodontic short courses within the Asian Pacific Region. We would like to propose that all such courses be sanctioned/endorsed by the National Orthodontic Association of the country concerned to safeguard the standards of teaching and practice of orthodontics within the region and safeguard our patients.

\section{Proposer}

Dr. Shalene Kereshanan

President,

Malaysian Association of Orthodontists

3.6 Proposal from Association of Phillipine Orthodontists (APO)

Since the delegates to the President's Summit are also members of the WFO / APOS, then our mission should also be in line with those of our umbrella organizations. One item that could be included in the agenda is for each member President to furnish the group with a list of accredited universities offering postgraduate courses in Orthodontics from their respective country. We could also come up with a speaker's bureau or a listing of speaker's from the different countries, with their cv's and lecture topics, who are willing to share their expertise in our field of specialization.

\section{Proposer}

Dr. Jose Rivera

President,

Association of Philippine Orthodontists

3.7 Proposal from Pakistan Association of Orthodontist (PAO)

1. It would be very practical and uniform if we could develop a universal examination system (starting from postgraduate level orthodontics), in which all the students from all parts of world can appear and the diploma/degree awarded is acceptable and registerable with all the registering bodies of 
the world. This I am wrinting in particular reference to the developing world. The students from these countries have to go abroad for their postgraduate studies and later on for jobs. They have to face problems when thay come back to their homeland when that particularly diploma/degree is not registered. Similarly when they apply for the jobs in different parts of the world, they have to face the same hurdle. This is because the diploma/degree of one country has not got the same weightage in other countries.

2. Student exchange programme would be another way of exchange of ideas and knowledge.

\section{Proposer}

Professor, Dr. Amjad Mahmood,

Immediate Past President,

Pakistan Association of Orthodontists

\subsection{Proposal from Indian Orthodontic Society (IOS)}

1. Membership Criteria's Lack of Uniformity: There are differing criteria in granting membership by individual national orthodontic Associations/Societies to its members.

These may differ as follows:

a) Qualifying standards: For granting full membership (with all rights including voting) to applicants, Indian Orthodontic Society (IOS) insists on a 3 year PostGraduate Training Degree (MDS) program with a dissertation component from a recognized institution before allowing the applicant a membership status. Though a few members without proper MDS in Orthodontics were given either Associate/Affiliate memberships in the yearly years, now, these classes of membership are not 'open' anymore since a few decades. Likewise, the duration of an MDS Program in Orthodontics did differ in the past from University that one did qualify from, over the years a much needed uniformity has been established for all recognized MDS programs.

Those with lesser qualifications (Diplomas, or, Overseas Training through Programs without a Dissertation Component) that are deemed inadequate by the Governing Council as compared to the equivalent of the uniform code/syllabus for all national training colleges in India, are not considered worthy of membership to IOS at all. The Governing Council for Dental Education in India closely examines the transcript of the Program of every applicant. In some cases, it is inferior to the set standards, the program is not acceptable to consider that professional to be worthy of being on the teaching staff for MDS students. For example some Universities/Dental Schools in Russia offer a MS program that involves just a handful of clinical cases to be treated by the trainee before being granted a Degree.

b) Opportunities offered: IOS also does not permit nonorthodontists to present free-communication oral papers or poster presentations that vie for any awards, or, even to attend the Meetings/Conferences.
The notable exception to the abovementioned rule, as per IOS norms, is for Invited Faculty who:

i. Render Guest Lectures

ii. Participate in a Symposium

iii. Conduct Pre-congress or Post-congress Courses

c) Rights: IOS does not grant Voting rights and/or the right to contest Elections for being an Office-bearer to anyone but Full Members.

It is a given that various countries will have differing concerns/policies regarding the protocol adopted for granting membership to their respective Orthodontic Associations. That is quite acceptable.

THE PROBLEM: When criteria differ between Countries to Countries for being given membership to their Orthodontic Association/Society, in an International Meeting, it may offer tricky problems for the host nation to accommodate requests for registration and /or presentations especially if any of those overseas delegates wishing to be registered have been giving/conducting Hands-on Courses in training nonorthodontists to do orthodontic treatment with Fixed Appliances. I am sure, qualified Orthodontists the world over detest this as it adversely affects their business prospects directly.

A few questions, which are rather tricky, do pop-up for the IOS who shall be hosting a true, recognized and endorsed International Orthodontic Conference for the first time in 2012:

- Can / should such members from an Overseas Nation/ Association, or, other members who are not Qualified Orthodontists (read that as General Dentists, mostly) be refused Registration by the Host Nation / Association for an Orthodontic Meeting / Conference?

- Will the Host Nation/Association, if it were to deny some overseas members a registration, be considered to be kind of transgressing on the rights of that particular National Association/Society/Group (who is an integral part of either WFO or APOS)?

- What kind of Registration Fee will apply for such members who are non-orthodontists? Should they be charged higher fees? Should the parent organization be expected to supply an updated list of its members that segregates qualified orthodontists from the other members?

- Though the issue of "Proper Training", or, "Qualified Orthodontists" will need considerable effort in defining for various countries/their Orthodontic Associations; it is a fact that, in a mixed gathering, the nature of questions asked of a Faculty will often be at a totally different level when the audience has General Dentists and Orthodontists. Those of us who have had an opportunity to lecture 
to such a 'mixed audience' will perhaps nod their heads in agreement on this one.

1. Menace of Orthodontists conducting Hands-on Courses for General Dentists: Assuming that most of us do agree this to be a menace, how can such a person be dissuaded from being engaged in such an activity? Or, before that, please think if such an activity should be attempted to be curbed at all or not? Assuming the answer to be YES, I feel that the issue has 2 ramifications: one at a domestic level, and the other one at an international level.

Domestic Level: If such a person is a member of a particular Organization and is running such an activity within his/her member country, it is purely the problem of that Association / Society / Nation. For example, if I am engaged in such an activity (of conducting hands-on courses, or, running term-courses over months and years to 'train' non orthodontists, my Society, the Indian orthodontic Society should be left to deal with the problem.

International Level: However, if, I were to go another Country: let's say, Bangladesh / Pakistan / Sri Lanka and collect hefty fees in "training" General Dentists there, upon a complaint from that Nation's Association to my parent Association through the aegis of either APOS or WFO (of whom my National Association is a member of), can no action be taken? If my Association, after being offered a proof of my unethical activity, still chooses to turn a blind eye, can some punitive measures not be taken against my Association to spur it on to the correct path? Such as:

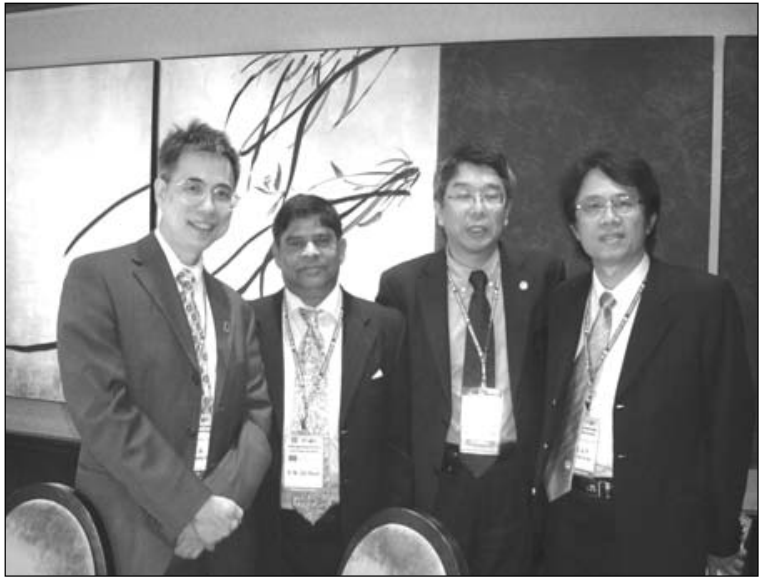

During Summit Meeting: from left to right Dr. Yen, Head Internationa Affairs, TAO, Dr. Hossain, Secretery, BOS, Dr. Hong, President, TAO. a) Rendering that Association inadmissible to have any member from it to be allowed to contest for any post in the Executive for say, a specified period of time (5 years).

b) Not allowing the said Association a vote on any matter for a specified period of time.

c) A hefty financial penalty to the concerned Association.

d) Rendering that individual a persona non grata and removing him/her from any post immediately?

e) Or, one or more, or, all of the above?

If we do not think of each-other's interests, we are not really getting the maximum of our International Organizations. Are we?

Proposer

Dr. Girish Karandikar

President, Indian Orthodontic Society

Hon Treasurer, Asian Pacific Orthodontic Society

\subsection{Adjournment}

TAO President Dr. Horng close the meeting and after that a photo session was conducted by the host's official photographer. A few memorial photographs are inserted.

Before adjournment of the summit meeting, I on behalf of the president BOS Prof. Dr. M.E.Haq, expressed my heartiest gratitudes for inviting me and placing our agendas on the top of the list that was discussed. Congratulation TAO and 2nd WIOC organizing committee for their great success and fulfillment.

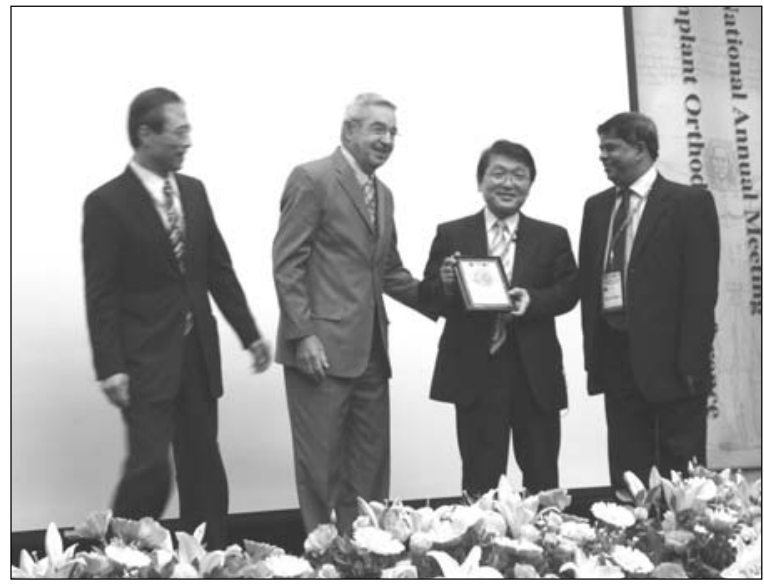

During Scientific Session: from left to right Dr. Y. Asai, Vice President, JAO, Dr. WH Dekock, Secretery General, WFO, Dr. Y. Watanaba (Japan), Dr. Hossain, Secretery, BOS

\section{Correspondence}

Dr. Md. Zakir Hossain BDS, PhD

Professor \& Head, Dept of Orthodontics \& Dentofacial Orthopedics

Dhaka Dental College \& Hospital, Mirpur-14, Dhaka-1206, Bangladesh

Secretary General, BOS

E-mail: hossainzorth@yahoo.com 